\title{
BRASIL/ARGENTINA: APONTAMENTOS SOBRE UMA ETNOGRAFIA PARA A ESCOLA NA AMÉRICA LATINA ${ }^{1}$
} SANDRA FÁTIMA PEREIRA TOSTA • WESLEI LOPES SILVA

\section{RESUMO}

Este texto parte de uma pesquisa que teve como objetivos analisar o referencial teórico-metodológico proposto pelo Grupo de Pesquisa do Departamento de Investigaciones Educativas do Centro de Investigación y de Estudios Avanzados del Instituto Politécnico Nacional - DIE-Cinvestav-IPN - do México e sua apropriação por pesquisadores de programas de pós-graduação no Brasil e na Argentina, a partir dos anos 1980. Sua justificativa está na alta recepção que a proposta do DIE alcançou na América Latina, particularmente nos referidos países, sendo uma outra leitura possível da escola em suas dinâmicas cotidianas e na relação com a sociedade, em contraposição às pesquisas orientadas pelas "teorias da reprodução". Trata-se de uma pesquisa em perspectiva comparada, do tipo documental, na qual buscou-se demarcar o estado do conhecimento da pesquisa educacional na interface com a História e a Antropologia no Brasil e na Argentina.

ETNOGRAFIA • ESCOLAS • BRASIL • ARGENTINA

Agradecemos aos demais pesquisadores do Grupo de Pesquisas e Estudos em Educação - Educ - do Programa de Pós-graduação em Educação da Pontifícia Universidade Católica de Minas Gerais Prof. Dr. Gilmar Rocha (Educ/Universidade Federal Fluminense), Profa. Dra. Carla Linhares Maia (Educ/Universidade Federal de Minas Gerais) e aos bolsistas de iniciação científica na época Aline de Castro Caldas, Adriana Oliveira, Camila Rodrigues Maltêz, Silmara Coelho Reis e Silva e Simon de Oliveira Martins, que participaram da investigação da qua se origina este texto. Agradecemos também à Fundação de Amparo à Pesquisa do Estado de Minas Gerais - Fapemig - e ao Conselho Nacional de Desenvolvimento Científico e Tecnológico - CNPq - pelo financiamento da pesquisa.

\section{BRAZIL/ARGENTINA: REFLECTIONS ON AN ETHNOGRAPHY FOR LATIN AMERICAN SCHOOLS}

\section{ABSTRACT}

This text is based on a study that aimed to analyze the theoretical-methodological framework proposed by the research group of the department of Investigaciones Educativas do Centro de Investigación y de Estudios Avanzados del Instituto Politécnico Nacional - DIE-Cinvestav-IPN - of Mexico, and its use by researchers of graduate programs in Brazil and Argentina, since the 1980s. It is justified by the high acceptance of the DIE proposal in Latin America, particularly in the countries mentioned above. It can offer another possible interpretation of the school in its everyday dynamics and in its relationship with society, as opposed to studies guided by the "theories of reproduction". It is a study in comparative perspective, of documentary type, which sought to define the state of knowledge in educational research in its interface with history and anthropology in Brazil and in Argentina. 


\section{BRÉSIL/ARGENTINE : RÉFLEXIONS SUR UNE ETHNOGRAPHIE DE L'ÉCOLE EN AMÉRIQUE LATINE \\ RÉSUMÉ}

Ce texte est basé sur une étude dont l'objectif était d'analyser le référentiel théorique, méthodologique proposé par le groupe de recherche du Departamento de Investigaciones Educativas du Centro de Investigación y de Estudios Avanzados de l'Instituto Politécnico Nacional [Département de Recherche en Éducation du Centre de Recherche et d'Études Avancées de l'Institut Polytechnique National du Mexique] - DIE-Cinvestav-IPN, au Mexique, ainsi que son appropriation par des chercheurs au Brésil et en Argentine, à partir des années 1980. Il se justifie par l'accueil très favorable qu'a reçue la proposition du DIE en Amérique latine, et plus particulièrement dans les pays mentionnés ici, car il rend possible une autre lecture de l'école, dans ses dynamiques quotidiennes et son rapport avec la société, par opposition aux recherches mobilisant les "théories de la reproduction ». I s'agit d'une étude comparée, de type documentaire, dans laquelle on a cherché à dresser l'état de la connaissance de la recherche en éducation dans son interface avec l'Histoire et l'Anthropologie au Brésil et en Argentine.

ETHNOGRAPHIE • ÉCOLES • BRÉSIL・ARGENTINE

\section{BRASIL/ARGENTINA: APUNTES SOBRE UNA ETNOGRAFÍA PARA LA ESCUELA EN AMÉRICA LATINA \\ RESUMEN}

Este texto parte de una investigación que tuvo como objetivos analizar el referencial teórico-metodológico propuesto por el Grupo de Investigación del Departamento de Investigaciones Educativas del Centro de Investigación y de Estudios Avanzados del Instituto Politécnico Nacional - DIE-Cinvestav-IPN - de México y su apropiación por investigadores de programas de postgrado en Brasil y Argentina a partir de los años 1980. Su justificación está en la alta recepción que la propuesta del DIE alcanzó en América Latina, particularmente en dichos países, siendo otra lectura posible de la escuela en sus respectivas dinámicas cotidianas y en la relación con la sociedad, en contraposición a las investigaciones orientadas por las "teorías de la reproducción”. Se trata de una investigación en perspectiva comparada, del tipo documental, en la cual se buscó demarcar el estado del conocimiento de la investigación educativa en interrelación con la Historia y la Antropología en Brasil y Argentina. 
Á ALGUMAS DÉCADAS, ESPECIALMENTE A PARTIR DOS ANOS 1970 NO BRASIL, A educação vem alargando seu olhar para as dinâmicas socioculturais que envolvem os processos educativos a fim de analisar e compreender essas realidades. Nesse intento, ante a complexidade que as envolve, tem-se buscado investigar o cotidiano educacional a partir dos diversos agentes envolvidos, dos lugares que ocupam, da multiplicidade de interações que desenvolvem, dos distintos meios pelos e nos quais tais processos acontecem, dentre outros aspectos e fenômenos (DAUSTER, 2007; GUSMÃO, 2008; ROCHA; TOSTA, 2009; PEREIRA, 2010). A busca por um olhar antropológico incide na conversão de novas luzes sobre as práticas educacionais, especialmente ao problematizar a asséptica representação da educação como transmissão/aquisição de cultura que muito pautou os estudos sobre a educação e a escola, a qual considera que essa instituição condiciona os sujeitos aos padrões sancionados e reificados socialmente. Para as chamadas “teorias reprodutivistas”, até então hegemônicas, o sistema escolar estatal era considerado um aparelho ideológico de Estado (ALTHUSSER, 1998), sendo a escola seu principal componente nas sociedades modernas, em que, pressupunha-se, não haveria condições de renovação e mudança, tal a sua conformação ao status quo. Esse enfoque costuma(va) deixar de lado as ações concretas que envolvem as vidas dos sujeitos, seu poder de subversão e agência, por exemplo.

Em que pese a questão dos diferentes aspectos culturais presentes no interior das escolas, é preciso considerar, no entanto, que 
a educação nunca gozou de muito prestígio junto aos antropólogos ${ }^{2}$ no Brasil. Só a partir dos anos 1980 o cenário dos programas de pós-graduação no Brasil começou a se modificar lentamente. O número de dissertações e teses que discutem a educação indica o aumento de interesse pela temática, bem como a presença de debates sobre a educação em congressos, seminários e associações aponta a atenção que a área começa a despertar.

Se a antropologia tem levado a cabo pouco investimento com relação ao tema da educação, o mesmo não tem ocorrido no caso da educação em sua aproximação com a área da antropologia. De imediato, dois fatores parecem contribuir para o prestígio da antropologia na educação no Brasil desde, pelo menos, a década de 1990: de um lado, a globalização da economia aliada à condição da pós-modernidade trouxe a questão da diferença e da diversidade cultural para o centro da vida social contemporânea; de outro lado, a antropologia parece preencher, hoje, a lacuna deixada após a expulsão da filosofia, dentre outras disciplinas, do campo educacional a partir da década de 1970. Em uma pertinente análise sobre a cultura universitária, Bosi (1992) indica que nessa época houve um decréscimo progressivo do ensino humanístico tradicional.

\footnotetext{
Toda cultura superior acaba procurando avidamente significados e valores no seu trabalho, e é precisamente nessa busca que as tendências formalistas começam a alterar-se, cindindo-se: em um movimento para dentro, de enrijecimento extremo e epigônico; e em uma superação que desemboca na negação da negação: a análise formal é então relacionada com o sentido da expressão e da comunicação, sentido interpretável ora em termos psicanalíticos ora em termos histórico-sociais. (BOSI, 1992, p. 310)
}

De resto, a penetração da proposta da "etnografia educacional" de Rockwell e Ezpeleta (1989), do Grupo de Pesquisa do Departamento de Investigaciones Educativas do Centro de Investigación y de Estudios Avanzados del Instituto Politécnico Nacional - DIE-Cinvestav-IPN -, nos programas de pós-graduação em educação, tem motivado em muito essa aproximação. Acrescente-se a isso a larga disseminação dos estudos culturais (cultural studies) que, muitas vezes, têm contribuído de forma impensada na formação de certos modismos (GUSMÃO, 2008).

Seduzidos pela ideia do "trabalho de campo" e pelo charme enigmático da palavra etnografia, nem sempre bem compreendida, os educadores em geral não procedem a uma reflexão epistemológica exigida por estas práticas que, no campo da antropologia, são constitutivas de sua tradição identitária. Para Rockwell (1986), a etnografia levada a cabo por profissionais que advêm de outras áreas e que não tiveram do Educ dedica-se justamente a essa questão. Para se conhecer mais a respeito, consultar: Relatório Técnico Diálogos nas fronteiras: a educação como objeto de investigação na antropologia brasileira. Belo Horizonte: PUC-Minas, Fapemig, 2016 
formação em antropologia ou em ciências sociais, em geral, realiza-se por meio de uma urdidura diversa de concepções, práticas e usos que, quase inevitavelmente, recaem na redução instrumental e puramente casuístico no fazer etnográfico.

A partir dos debates e do posicionamento assumido pelo grupo de pesquisadoras do DIE, a pesquisa etnográfica adquiriu na América Latina características muito peculiares devido à apropriação de perspectivas críticas, resistência às modalidades empiristas e busca de uma coerência teórica, debatendo com outras perspectivas qualitativas, inclusive com a pesquisa participante e propondo uma perspectiva crítica de fazer etnografia, visto que Rockwell e Ezpeleta (1989) consideravam a etnografia clássica positivista e colonialista.

A maior preocupação do grupo mexicano tem sido ampliar o alcance teórico da construção do conhecimento e da descrição de processos simbólicos que documentem as particularidades locais sem, contudo, desconsiderar sua relação com o marco teórico geral no qual se situam, de modo a integrar o estudo etnográfico a um contexto amplo sem perder de vista a opção histórica a partir da qual o pesquisador analisa a sociedade. O diálogo com a teoria, desde as primeiras etapas da pesquisa, torna-se uma premissa fundamental; assim, algumas categorias são definidas antes de entrar em campo e os etnógrafos estabelecem contínuos contrastes entre as referidas categorias e os processos que intervêm no cotidiano escolar de acordo com a sua interpretação.

As pesquisadoras pretendem, assim, contribuir teórica e metodologicamente para a investigação do cotidiano ${ }^{3}$ escolar, evidenciando como cada escola, por ser uma construção histórica e social particular, somente pode ser entendida por meio do conhecimento profundo do seu cotidiano. É através dele que podem ser apreendidos diferentes processos que a constituem e como os sujeitos nela envolvidos constroem e reconstroem saberes e práticas em suas interações. Além disso, qualquer aspecto que pretenda ser pesquisado e adequadamente compreendido sobre professores, alunos, formação docente, entre outros, precisa ser situado no contexto específico de cada instituição escolar. A partir destas premissas, Rockwell e Ezpeleta (1989) oferecem algumas indicações para olhar para dentro da escola, para sua realidade concreta e, ao mesmo tempo, para pensá-la inserida em um contexto histórico mais amplo, isto é, para sua dimensão de historicidade e, por isso mesmo, sujeita à mudança social.

Pois bem, é nesse contexto que destacamos a contribuição teórico-metodológica do DIE-Cinvestav e sua presença no campo da pesquisa e contra-hegemonia em Gramsci (1979) em educação no Brasil e na Argentina e justificamos nosso interesse em aprofundar o conhecimento sobre este enfoque da etnografia no estudo da escola na América Latina, como proposto pelo DIE. Desse modo, a proposta do presente artigo se ancora nas seguintes questões: qual o 
referencial teórico que embasa sua leitura da antropologia e a proposta de investigações etnográficas? Em que aspectos esta proposta se distingue das abordagens clássicas da etnografia? Como pesquisas no Brasil e na Argentina se apropriam desse referencial teórico-metodológico?

A partir de uma reflexão epistemológica em perspectiva comparada, o objetivo deste artigo é apresentar os resultados de uma investigação sobre a relação entre a antropologia e a educação nos contextos brasileiro e argentino, tendo como ponto de partida a "etnografia educacional”, proposta pelas pesquisadoras Elsie Rockwell e Justa Ezpeleta, representantes paradigmáticas do DIE-Cinvestav-IPN do México.

Em Etnografia para a América Latina: um outro olhar sobre a escola no Brasil, pesquisa realizada entre 2009 e 2011, pelo Grupo de Pesquisas e Estudos em Educação - Educ - do Programa de Pós-graduação em Educação da Pontifícia Universidade Católica de Minas Gerais, financiada pela Fapemig (TOSTA et al., 2011), e, posteriormente, em projeto na comparação com a Argentina, financiado pelo CNPq (TOSTA et al., 2012), buscou-se, de um lado, aprofundar e ampliar o entendimento sobre o campo de estudos da "etnografia educacional" desenvolvida a partir da proposta de Rockwell e Ezpeleta (1989) e, de outro, em vista da acolhida desta proposta no Brasil e na Argentina, compreender o processo de sua apropriação pelos pesquisadores em educação desses dois países

O resultado, bastante positivo, apontou também os limites do uso dessa proposta etnográfica no campo da educação no Brasil. Resumidamente, chegou-se à seguinte conclusão:

Pode-se dizer que a leitura das dissertações e teses que procuraram inspiração na proposta do DIE-CINVESTAV-IPN do México trouxe grande contribuição para o conhecimento do que "se passa nas escolas", ou seja, uma compreensão bastante situada no interior da escola, do seu cotidiano, dos espaços, das dinâmicas e práticas que acontecem nesta instituição e que, raramente, eram documentadas ou significadas em pesquisas de natureza quantitativa e nas chamadas investigações orientadas pelas teorias da reprodução. [...] Contudo, observou-se pouco aprofundamento ou apropriação "global" da proposta do DIE, pouco conhecimento e discussão dos fundamentos e dos autores e perspectiva que baseiam a proposta deste Departamento. Pode-se afirmar, a partir dos trabalhos analisados, que a perspectiva das autoras e autores mexicanos possibilitou uma aproximação e (adoção) da etnografia, assumida como uma nova e fecunda perspectiva para as pesquisas no campo da educação, especialmente nas escolas na América Latina. Mas, o fato é que essa aproximação e adoção não vieram sempre seguidas de um diálogo mais profundo e necessário com a antropologia e seus aportes teóricos e metodológicos. 
Ele ocorreu, muitas vezes, por via de uma "importação" do método etnográfico despido do referencial teórico originário. Fato que reitera o que alguns outros estudos similares já observam: certa confusão existente entre o que é o empreendimento intelectual na antropologia para se fazer uma etnografia, com o estudo qualitativo ou a observação participante. Dito de outra maneira, a apropriação metodológica é entendida ou confundida, muitas vezes, com procedimentos como convivência e observação na escola ou com a observação participante, que é a referência que mais aparece nas pesquisas analisadas. (TOSTA et al., 2011, p. 70-71)

A pesquisa trouxe outras novidades e necessidades, sendo a aproximação com o caso da Argentina a principal delas. O DIE e a "etnografia educacional” de Rockwell e Ezpeleta (1989) também se fazem fortemente presentes na história da educação e da antropologia argentina, porém, de maneira diferenciada daquela observada no Brasil. Pode-se dizer que a penetração das ideias desenvolvidas no âmbito do DIE no Brasil ocorre via os estudos realizados no campo da educação, diferentemente do que parece acontecer no caso da Argentina, onde a penetração das ideias do DIE se faz via o campo da antropologia mobilizada pelos estudos de problemáticas educacionais.

\section{OS CAMINHOS DA PESQUISA E AS CONTRIBUIÇÕES DO DIE}

Com o intento de evitar todo e qualquer reducionismo acerca da educação e da escola e buscando coadunar as contribuições de diferentes autores e perspectivas teóricas, Elsie Rockwell e Justa Ezpeleta buscam articular uma (nova) antropologia da educação e, especialmente, o desenvolvimento de um fazer etnográfico próprio às investigações na escola, a fim de que se possa conhecer e compreender, o mais amplamente possível, como essa instituição se constitui e atua diante da multi e interculturalidade, por exemplo, e das demais forças que a engendram.

É inegável pensar que a escola, bem como outros espaços educacionais, compõe-se de realidades experimentadas e vividas que se fazem e se refazem continuamente por meio de processos culturais que engendram a vida humana em seu interior (GUSMÃO, 1997) e que, portanto, não podem ser pensados a partir de uma imagem estanque e homogeneizante. Isso quer dizer que, embora ainda se encontrem presas a uma lógica racional universalista, as escolas não são todas iguais, visto que cada uma delas tem uma cultura particular, com sistemas de classificação e produção de simbologias próprios, distintas formas de sociabilidades e rituais que compõem seu cotidiano, bem como diferentes modos de hierarquizar seus agentes na construção de suas práticas (ROCHA, 2012). 
Reconhecer a escola como um espaço sociocultural implica a crença de que ela não está isolada da vida social e que, dentre outros aspectos, seu interior é perpassado e constituído por diferentes atores, de diversas culturas, com vários saberes e múltiplas formas de ver e experimentar o mundo. Em outras palavras, importa examinar que as escolas "se realizam nos modos como os sujeitos as pensam e as vivenciam em seus contextos” (ROCHA; TOSTA, 2009, p. 135).

A partir deste ponto de vista, e para entender a particularidade da proposta téorico-metodológica de Elsie Rockwell e Justa Ezpeleta, é importante reconstruir a trajetória do seu grupo de pesquisa e buscar sua origem e principais influências do contexto histórico em que surgiu e desenvolveu-se. Assim, pode-se localizar o início deste processo nos anos 1970, quando países latino-americanos eram dominados por regimes militares. Neste período podemos identificar uma profusão de movimentos de educação popular predominantemente influenciados pelo pensamento de Paulo Freire e com o apoio de setores vinculados à Igreja Católica e a grupos políticos de esquerda. Época em que as "teorias reprodutivistas” eram hegemônicas, as experiências pedagógicas inovadoras aconteciam fora da escola, na educação popular e não formal e não no sistema formal de ensino, em que, pressupunha-se, não haveria condições de renovação e mudança, tal a sua aderência incondicional às classes dominantes e ao status quo.

Com o processo de democratização nos anos 1980, vários países latino-americanos (México, Colômbia, Peru, Brasil, Argentina, entre outros) começaram a buscar formas de transferir às escolas as experiências pedagógicas inovadoras desenvolvidas nos projetos de educação popular. Educadores críticos participaram de reformas educativas em seus países, como foi o caso do México, visando lutar por uma educação pública de qualidade. O grupo de pesquisadoras do Departamento de Investigación Educativa - DIE - participou desses projetos, fez a releitura dos clássicos do marxismo, principalmente nas interpretações de Georg Lukács (1978) e Antônio Gramsci (1979), e também a leitura de teóricos contemporâneos como Louis Althusser (1998), Agnes Heller (1994), Jurgen Habermas (1987), Pierre Bourdieu (1992), Edward Thompson (1987), entre outros, e desenvolveu um debate crítico com as perspectivas estruturalistas e fenomenológicas, em busca de concepções que as superassem.

Nesse intenso debate intelectual, Rockwell e Ezpeleta (1989), ao problematizarem o lugar da instituição escolar na sociedade capitalista, reconhecem a contribuição das perspectivas macrossociais e políticas para a análise da relação entre escola e sociedade, porém, questionam os limites de determinadas categorias marxistas para compreender a realidade escolar na América Latina. Esta reflexão teórica possibilita a recuperação do conceito de Estado em Gramsci (1979), definido como “sociedade civil mais sociedade política, ou seja, hegemonia revestida 
de coerção" (COUTINHO, 1976). A sociedade civil assume em Gramsci um novo sentido, expressando o momento da persuasão e do consenso, o que permite olhar a escola a partir de outro ângulo, ou seja, possibilita pensar um conceito emancipatório de educação porque, para este autor, se é na sociedade civil que circulam ideologias, é nela, também, que podem ocorrer contraideologias que buscam corroer o senso comum, fomentado pela ideologia dominante.

Com efeito, para Rockwell e Ezpeleta (1989), a escola seria um dos lugares privilegiados do encontro entre o Estado e as classes populares. É onde estão presentes os interesses divergentes e antagônicos entre o Estado, representante histórico das classes dominantes, interessado em manter o status quo, e as classes populares que veriam na escola a chance de superar a exploração e de melhorar sua condição de vida. Nesta direção, tais classes se apropriariam, cotidianamente, dos conteúdos educativos para reelaborá-los fora do controle estatal e em favor de seus interesses e lutas. Assim, as pesquisadoras também introduzem no campo da educação o conceito de cotidiano e de vida cotidiana na perspectiva proposta pela filósofa Agnes Heller (1994), apontando o estudo do cotidiano escolar como um caminho para compreender a natureza da relação entre o Estado e as classes populares, mediada pela escola. Para tal, elas afirmam que é necessário reavaliar as categorias utilizadas pelos estudos realizados na escala macro (classe social, sistema social, reprodução, dominação, entre outras), repensá-las ou abandoná-las, a fim de encontrar novas categorias mais adequadas à escala micro do cotidiano escolar.

Para as pesquisadoras do DIE, portanto, há vida cotidiana em toda parte. Assim, o conceito de cotidiano escolar permite recuperar a heterogeneidade da escola, sendo que a única forma de dar conta desta realidade é tomá-la como uma construção histórica. Assim é que, do ponto de vista de Heller, mostrar o cotidiano é historicizá-lo. Em outros termos, a vida cotidiana está no âmbito da história e não fora dela, argumento que traz grande potencialidade para os estudos sobre a escola ou na escola. Esta perspectiva nos permite pensar os professores e os alunos como

[...] sujeitos que incorporam e objetivam, a seu modo, práticas e saberes dos quais se apropriaram em diferentes momentos e contextos de vida, depositários que são de uma história acumulada durante séculos. (ROCKWELL; EZPELETA, 1989, p. 28)

As pesquisadoras dialogam com a perspectiva fenomenológica, cujo objetivo é aprofundar a interpretação dos significados socialmente compartilhados pelos indivíduos em interação, o que implica considerar a intencionalidade, as vozes dos sujeitos, os estilos de interação e o 
contexto geral no qual se dá a produção específica de textos simbólicos. Dessa maneira, as autoras questionam a definição do processo de pesquisa somente em termos de interpretação de significados, deixando fora da análise outros processos sociais susceptíveis de serem estudados. A partir desses debates e do posicionamento assumido pelo grupo de pesquisadoras do DIE, a pesquisa etnográfica adquiriu na América Latina características muito peculiares em função da apropriação de perspectivas críticas, da resistência às modalidades empiristas e da busca de uma coerência teórica, debatendo com outras perspectivas qualitativas, inclusive com a pesquisa participante, e propondo uma nova forma de fazer etnografia.

A maior preocupação dos pesquisadores do DIE tem sido ampliar o alcance teórico da construção do conhecimento e da descrição de processos simbólicos que documentem as particularidades locais, sem, contudo, desconsiderar sua relação com o marco teórico geral no qual se situam. Assim, buscam integrar o estudo etnográfico a um contexto amplo sem perder de vista a opção histórica a partir da qual o pesquisador analisa a sociedade.

A articulação entre a reflexão teórica e o trabalho empírico permitiu que os pesquisadores do DIE observassem, descrevessem e analisassem situações do cotidiano escolar, construindo novas relações que possibilitaram a releitura da escola articulando novos conceitos e categorias. Nessa abordagem, que busca superar as dicotomias como aquelas mencionadas neste texto, coexistem na escola uma história documentada e uma não documentada; entrecruzam-se determinações civis e estatais; estão presentes o homogêneo e o heterogêneo. A ideia, então, é pensar no processo de construção social da escola, ou seja, a escola como versão local e particular no movimento histórico. Nesse sentido, Rockwell e Ezpeleta (1989) propõem avançar teórica e metodologicamente nas investigações sobre a realidade escolar, superando as ferramentas teóricas utilizadas anteriormente para pensar a instituição e que não permitiam enxergá-la em sua concretude e não davam a ela centralidade e nem visibilidade. Para as autoras,

[...] o intrincado conceitual existente para observar a escola, para abordá-la como unidade do sistema escolar, servia normalmente para comunicar o que nela não existia para elencar suas deficiências e carências. (ROCKWELL; EZPELETA, 1989, p. 10)

Diversamente, as autoras buscam estudar a escola em sua positividade, não como o bom, mas no sentido do existente, do que podemos enxergar concretamente na realidade de cada escola. Elas buscam conhecer a escola de outro modo, não pelas suas carências, mas sim pelas contradições que nela se apresentam e que podem permitir as 
necessárias mudanças. É preciso conhecê-la por dentro, na sua dimensão micro, sem, contudo, perder de vista o movimento social mais amplo do qual é parte. Nessa direção, qualquer aspecto que se queira pesquisar e adequadamente compreender sobre professores, alunos, formação docente, entre outros elementos que configuram o cotidiano na escola, precisa ser situado no contexto específico de cada instituição escolar. Enfim, Rockwell e Ezpeleta (1989) oferecem inúmeras indicações para "mirar desde abajo" da instituição escolar, para sua realidade concreta e, ao mesmo tempo, para pensá-la inserida em um contexto histórico amplo.

Com estes argumentos as autoras direcionaram seus estudos sobre a análise e a busca de uma nova proposta de investigação da escola. Entravam em campo as contribuições da etnografia, fazer essencial da Antropologia, buscando transformar, a partir do cotidiano das escolas - ao mesmo tempo em que indo além da cotidianidade - o não significativo ou pelo de sentidos.

A partir dessa proposição, o que seria observável no contexto escolar? Nas palavras de Rockwell e Ezpeleta (1989, p. 1), seria "o que ocorre fora dos limites dos regimentos, fora da classe, 'fora de asamblea' fora da visita rotineira do supervisor". Ou seja, o resgate do vivido, tanto do instituído como do não instituído, não oficializado, mas que tem efetividade e existência concreta no dia a dia da escola, nas relações sociais estabelecidas entre todos os sujeitos envolvidos com a educação escolar. Em suma, para as autoras, aproximar-se da escola com a ideia de "vida cotidiana" significa algo mais que "chegar" e "observar" o que ocorre diariamente em seus corredores, salas de aulas, dentre outros espaços. Trata-se, antes, de uma postura teórico-metodológica, uma "orientação, de certa busca e de uma certa interpretação daquilo que pode ser observado na Escola" (ROCKWELL; EZPELETA, 1989, p. 2).

Suas contribuições para a investigação do/no cotidiano escolar expressam, no contexto em que foram formuladas, não só um novo tipo de conhecimento sobre a realidade escolar, mas, também, um compromisso de que esse conhecimento contribua para a transformação da realidade. Essa abordagem tem especial relevância por corresponder a uma intencionalidade política e educativa: "transformar a escola" (ROCKWELL, 1992).

Isto posto, de natureza bibliográfica e comparada, a investigação de onde parte este artigo se baseia no exame de dissertações e teses de Programas de Pós-graduação em Educação, no caso brasileiro, e de Programas de Pós-graduação em Antropologia da Educação e de Educação, no caso argentino, com a finalidade de inventariar o que já foi produzido acerca do diálogo entre antropologia e educação, a partir dos anos 1980. Com o objetivo de se alcançarem novas informações, esclarecimentos e interpretações em temas e ângulos ainda pouco explorados, a pesquisa bibliográfica enquanto procedimento metodológico visa, 
especialmente, à produção de conhecimento aprofundado de determinado assunto, do mesmo modo que se ocupa da constituição e desenvolvimento de um objeto de pesquisa. A esse respeito, deve-se considerar também que

[...] a compreensão do estado de conhecimento sobre um tema, em
determinado momento, é necessária no processo de evolução da
ciência, a fim de que se ordene periodicamente o conjunto de infor-
mações e resultados já obtidos, ordenação que permita indicação
das possibilidades de integração de diferentes perspectivas, apa-
rentemente autônomas, a identificação de duplicações ou contra-
dições, e a determinação de lacuna e vieses. (SOARES, 1989, p. 3)

Tendo como procedimento nuclear a pesquisa documental com vistas à comparação, a investigação seguiu os princípios básicos de identificação, compilação e fichamento das obras analisadas. E diante dos objetivos colocados e considerando a articulação entre dois campos do conhecimento - a antropologia e a educação -, a investigação e a análise se deram a partir do referencial teórico-metodológico hermenêutico-dialético, uma vez que essa perspectiva propõe a adoção de uma postura interpretativa, em que se buscam os sentidos e os significados do conteúdo dos textos coletados com base em uma revisão crítica na qual contradições, aproximações e distanciamentos podem ser mais bem dimensionados, ampliando novas perspectivas de entendimento.

A hermenêutica, em linhas gerais, tem como centro de interesse a compreensão dos significados dos fenômenos, nos quais as ações humanas podem ser abordadas enquanto "textos", que podem revelar muitos significados ocultos a partir de sua apreensão e interpretação. Tais textos se produzem e estão inseridos em determinado contexto sócio-histórico-cultural, ganhando significados e sentidos que escapam do controle de quem os produziu. Pode-se dizer, então, que eles têm vida própria, tratando-se de um fenômeno sociopolítico que obtém relevo no transcorrer da história. Assim, por meio de uma postura epistemológica que empreende esforço sistemático e metódico, a hermenêutica propõe buscar os significados e propósitos nas situações concretas da vida dos sujeitos, sendo a interpretação um destacado empreendimento nessa análise (MINAYO, 2002).

Já a dialética enquanto metodologia, de acordo com essa autora, pressupõe o estudo das oposições, considerando que o mundo é movimento e está em constante desenvolvimento, isto é, nada é estático ou hermético. O conhecimento, portanto, tratar-se-ia sempre de um diálogo, advindo de um processo de verdades relativas oriundas de uma verdade mais ampla. Na perspectiva da dialética, consequentemente, cada fenômeno traz em seu interior sua própria contradição, o que significa 
dizer que cada coisa é o que é em dado momento, uma síntese de sua afirmação e de sua negação. A partir desse ponto de vista, o cientista deve sempre considerar em suas investigações a contradição e o conflito, o "devir", o contexto histórico, como também a totalidade e a unidade dos contrários envolvidos.

Considerando-se, pois, que os fenômenos são social e historicamente construídos, a conjugação entre a hermenêutica e a dialética, de acordo com Minayo (2002), colabora para a transposição das limitações de cada método vislumbrado separadamente, constituindo em uma abordagem que engendra uma ótica teórico-metodológica compreensiva e crítica de análise da realidade social, sendo, portanto, o método

[...] mais capaz de dar conta de uma interpretação aproximada da realidade. Essa metodologia coloca a fala em seu contexto para entendê-la a partir de seu interior e no campo da especificidade histórica e totalizante, em que é produzida. (MINAYO, 2002, p. 231)

Em conciliação com a metodologia adotada, o que implica situar os documentos em seu contexto para que possam ser compreendidos, a investigação contou basicamente com dois níveis em sua análise: compreensão do contexto sócio-histórico em que foram produzidos os documentos na articulação antropologia-educação e suas repercussões nesse contexto, o que constitui o marco teórico fundamental para a análise; e interpretação a partir dos encontro dos fatos empíricos com as concepções teóricas, visto que os documentos precisam ser situados em uma estrutura teórica para que o seu conteúdo seja entendido. Trata-se aqui da descoberta da totalidade e de sua significação particular e geral, bem como das reflexões advindas da comparação entre Brasil e Argentina, a partir da leitura e exame do material (teórico-metodológico e empírico) selecionado que constituiu o corpus das investigações das quais partem as reflexões deste texto.

De natureza qualitativa, a intenção da pesquisa aqui apresentada não exclui, entretanto, o uso de dados quantitativos, pois consideramos que, partir de diversas abordagens, é possível situar melhor os dados no conjunto do contexto social investigado e, consequentemente, alcançar uma análise e interpretação mais complexa dos mesmos (SANCHIS, 1997). Essa conciliação busca, portanto, romper com a dicotomia que comumente envolve critérios quantitativos e qualitativos no exame de dados, perspectiva que pode ser bastante limitadora ou mesmo dolosa ao fazer científico, porque, de fato, não há (ou não deveria haver) uma oposição entre essas abordagens, visto que elas se integram e se complementam convenientemente, desde que haja como pano de fundo um modelo teórico substancioso (ROESSNER, 2000), moção que buscamos construir epistemológica e metodologicamente no desenvolvimento desta investigação. 


\section{ANTROPOLOGIA, ETNOGRAFIA E ESCOLA NO BRASIL}

Pelo que foi possível depreender, conforme mencionado, nas últimas duas décadas a antropologia começou a descobrir a educação. Este fato diz muito sobre a antropologia e a educação no Brasil na atualidade: de um lado, aponta para o amadurecimento e penetração da antropologia no estudo dos mais diversos temas, problemas e objetos sociais; de outro, a educação tem obtido atenção especial em termos de políticas públicas, por exemplo, com a promulgação, em 1996, da Lei de Diretrizes e Bases da Educação Nacional - LDB - e dos Parâmetros Curriculares Nacionais - PCN.

Na investigação denominada "Etnografia para a América Latina um outro olhar sobre a escola no Brasil”, durante o processo da pesquisa foram identificados e selecionados levantamentos em educação produzidos a partir dos anos 1980 no Brasil, que adotaram o referencial teórico metodológico do DIE-Cinvestav. Tais dados foram coletados junto ao portal da Coordenação de Aperfeiçoamento de Pessoal de Nível Superior - Capes -, sendo mapeadas, por meio do descritor “etnografia”, dissertações e teses produzidas no Brasil nos seus programas de pós-graduação em educação. ${ }^{4}$ Ao final desta coleta, que não aconteceu sem vários percalços de ordem técnica relativa aos acessos junto ao portal, foram selecionadas 1.192 produções, correspondendo a 973 dissertações e 219 teses. O conjunto das 1.192 produções selecionadas foi lido e analisado por meio dos dados apresentados em seus resumos. Identificado esse expressivo contingente de produções que mencionaram a etnografia em seus resumos, fez-se necessário avaliar em uma segunda leitura dos resumos das dissertações e teses a existência de indícios que possibilitassem à equipe de pesquisadores um maior entendimento acerca do uso da etnografia nas pesquisas selecionadas. Isto porque, na leitura dos resumos, foram encontradas inúmeras denominações referentes aos procedimentos metodológicos, o que impossibilitou uma percepção mais imediata e precisa dos trabalhos, além do fato de, em muitos casos, não haver nenhuma referência à metodologia usada nas pesquisas, como é de se esperar em um resumo.

Com o objetivo de nortear uma segunda leitura para reaproximação e análise dos resumos na tentativa de captar o mais fielmente possível o que os mesmos diziam do uso da etnografia nas investigações, foram definidas as seguintes "categorias":

- o cotidiano escolar em seus espaços, dinâmicas, condições materiais e no contexto da sala de aula;

- presença da relação escola/sociedade e escola/comunidade;

- dimensão da relação entre o "prescrito" e o "realizado" no cotidiano escolar: políticas públicas e políticas escolares (normas; regulamentos; currículo; regimentos e seus reflexos sobre a escola);

- compromisso da investigação com a mudança social, a partir de um olhar sobre a "existência real" da escola, não apenas para ocorreu em 2009 e, neste ano, o site da pesquisa apresentava disponiveis os anos de 1987 a 2008. 
diagnosticar carências e deficiências existentes, mas também indicando as manifestações cotidianas que orientam para a transformação da escola, indo “além do cotidiano".

Essa renovada análise dos resumos resultou em significativa queda no número de produções anteriormente selecionadas: do total de 973 dissertações, foram escolhidas 178, e, das 219 teses, selecionaram-se apenas 66, totalizando, assim, 244 trabalhos que, de acordo com o critério da região/número de pesquisas, passariam por outra seleção para leitura na íntegra dos textos e posterior análise crítica e situada nos objetivos deste projeto. Embora as referidas categorias tenham possibilitado uma leitura bem mais aproximada acerca do uso da etnografia nas pesquisas, outros aspectos também foram considerados. Além da grande quantidade de produções, os resumos destas 244 pesquisas ainda se mostraram inconsistentes, contendo informações que foram consideradas pelos pesquisadores insuficientes quanto ao entendimento da opção metodológica e do referencial teórico adotado pelos seus respectivos autores.

Tal constatação deu a partida para uma terceira leitura e análise dos resumos, a fim de que fosse contemplada a relação acima indicada por região e quantidade de trabalhos. Na seleção final das obras, foram localizadas 13 produções (seis teses e sete dissertações) que mencionaram explicitamente em seus resumos a utilização do referencial teórico para a etnografia proposto pelo DIE. Este dado foi considerado mais que seguro para que tais pesquisas fossem separadas para a leitura analítica. No entanto, não seria possível limitar a análise apenas aos resumos que indicavam o referencial teórico e metodológico do DIE, lembrando as dificuldades enfrentadas no que diz respeito à leitura dos mesmos, uma vez que muitos deles encontravam-se incompletos, com palavras grafadas de forma incorreta, além de não explicitar - em grande parte dos casos - o referencial teórico adotado na dissertação ou na tese. Afora as 13 pesquisas selecionadas, decidimos, então, pelo refinamento dos critérios da investigação e desta vez foram consideradas para leitura apenas as produções de doutorado. Tal decisão foi tomada tendo em vista que um dos pressupostos da etnografia é a exigência de um tempo alargado para a sua realização, com permanência prolongada do pesquisador na escola. Este critério adotado foi amparado na certeza, também, de que o curso de doutorado que pode ser concluído em até quatro anos e meio, no caso do Brasil, favorece o pressuposto de que o doutorando teve experiência de pesquisa acumulada na dissertação e mais tempo para o campo, fatores que, em princípio, viabilizariam a realização de uma etnografia. A partir de tal decisão, o corpus da pesquisa passou a ser constituído por 66 teses e sete dissertações. Desse total, foi escolhido, por meio de uma última leitura mais seletiva, um conjunto de trabalhos que atendiam ao critério de representatividade por região explicitada. 
Finalmente chegou-se a um número de 30 produções e, dentre elas, encontram-se as dissertações que mencionaram diretamente o uso do referencial teórico metodológico do DIE. ${ }^{5}$

\section{GRÁFICO 1}

TESES E DISSERTAÇÕES BRASILEIRAS SELECIONADAS PARA LEITURA E ANÁLISE

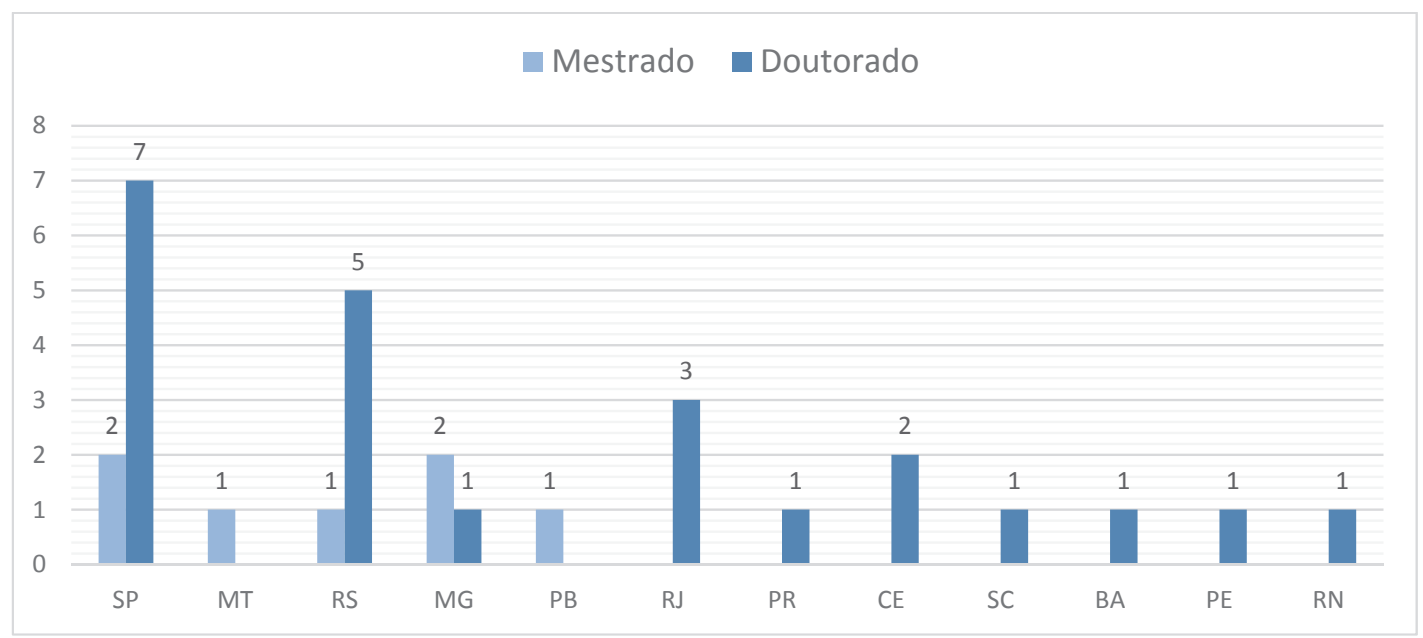

Fonte: Dados da pesquisa.

Os resultados sistematizados pela equipe de pesquisadores apontaram três pesquisas que, de fato, se constituíram em uma etnografia - tal como aquela proposta pelo DIE a partir do referencial teórico e metodológico em questão -, além de outras oito pesquisas que, apesar de não atenderem aos critérios, apresentaram alguma contribuição relevante relacionada a aspectos importantes do referido referencial. As demais 19 investigações nada diziam deste referencial e/ou não corresponderam em nenhum aspecto ao referencial da etnografia.

\section{ANTROPOLOGIA, ETNOGRAFIA E ESCOLA NA ARGENTINA}

No que tange à Argentina, à primeira vista, sua história da formação da antropologia se parece com a do Brasil ou de todas as "antropologias periféricas”. Afinal, também na Argentina, os primeiros modelos de explicação têm sua origem no "centro" e são importados do mundo anglo-saxão. Contudo, seguindo a sugestão de Oliveira e Ruben (1995), isso não impediu o desenvolvimento de "estilos de antropologia”, cuja caracterização explica-se, em parte, à luz do processo histórico, social e político de formação da nação. A antropologia argentina não foge à regra, em nosso entendimento.

De acordo com Neufeld (2011), foi em 1984, a partir do retorno à democracia (após o último período de governos militares naquele país), que a organização do subcampo disciplinar conhecido como Antropologia

5

Das 30 teses e dissertações, seis das indicadas para leitura na íntegra não foram disponibilizadas para a pesquisa pelo fato de não terem sido localizadas em suas bibliotecas de origem para envio à Biblioteca da PUC-Minas, através do sistema COMUT. A cópia de uma delas para uso na pesquisa não foi autorizada pelo autor. Uma das teses teve uma análise diferenciada por se tratar de uma pesquisa sobre o estado do conhecimento do uso da etnografia na pesquisa educacional. 
e Educação teve lugar nas universidades de Rosário, Buenos Aires e La Plata. Ainda segundo a autora, esse campo da etnografia foi se constituindo em meio à natureza multidisciplinar que marca as formações universitárias nas faculdades de educação. Os institutos de Antropologia e Ciências da Educação das universidades acima mencionadas logo conquistaram uma quantidade significativa de estudantes do campo da educação, que passaram a desenvolver pesquisas no âmbito da antropologia. ${ }^{6}$ É preciso destacar, no entanto, que os diálogos entre a etnografia e a educação tiveram seus antecedentes na Argentina, mesmo antes do período acima mencionado.

Desde essa perspectiva, pode-se deduzir que, de um modo geral, dois elementos destacam a forte presença de Elsie Rockwell e Justa Ezpeleta na construção da tradição etnográfica no campo da pesquisa em educação na Argentina. São eles: a participação de Elsie Rockwell na organização da Red de Investigaciones Cualitativas en Educación, a qual divulgou as primeiras discussões sobre a etnografia na Argentina; e o canal de comunicação estabelecido a partir da presença da argentina Justa Ezpeleta no México (no período da ditadura no país), o que resultou na produção teórica, em 1983, da dupla Ezpeleta e Rockwell acerca do enfoque etnográfico na pesquisa em educação.

Diferentemente das pesquisas brasileiras que buscaram trabalhar com a etnografia do DIE, ${ }^{7}$ as pesquisas argentinas mostraram um maior trânsito nos referenciais teóricos propostos por Elsie Rockwell, mais do que de seus escritos produzidos com Justa Ezpeleta ou Ruth Mercado, por exemplo. Estas são autoras dos primeiros tempos do DIE, suas fundadoras. Do mesmo modo, os estudos argentinos lidos e analisa-

Para Neufeld (2011, p. 4): "Esto tiene sus excepciones y bien importantes: en la Universidad Naciona de Córdoba, en donde la Licenciatura en Antropología no existía (se crea recientemente. en 2010) la investigación socioantropológica acerca de problemáticas educativas encontró su sede en el Instituto de Investigación María Saleme de Bournichon, de la Escuela de Ciencias de la Educación y en el Centro de Estudios Avanzados ambos de la Universidad Nacional de Córdoba".

Nestas, a principal obra de referência foi $A$ pesquisa participante, de Rockwel e Ezpeleta (1989). Outros autores utilizados com frequência foram: Agnes Heller, Antonio Gramsci, Antônio Nóvoa, Vygotsky e Adam Schaff. dos, de fato, conseguiram compreender as realidades escolares investigadas como um todo integrado, isto é, tanto na dimensão macro quanto na micro, em seus diversos aspectos. São exemplares os estudos de localidade, em bairros ou em determinadas comunidades caracterizadas por um grande número de migrantes rurais ou estrangeiros, indicando o interesse dos pesquisadores argentinos pelo viés da interação cultural entre diferentes etnias e identidades.

Sendo assim, não se pode deixar de afirmar que a relação entre a proposta do DIE e os estudos etnográficos em educação realizados na Argentina é muito mais estreita que no Brasil, dado que a formação em antropologia dos argentinos, na retomada do campo após os longos anos da ditadura militar naquele país, vai ocorrer de modo predominante no Instituto Politécnico do México - IPN -, onde está localizado o DIE. Bem diferente do que aconteceu no caso brasileiro das ciências humanas e sociais, em que numa antropologia ainda nascente e se consolidando não houve uma intervenção da ditadura militar no Brasil sobre estes pesquisadores. Já na Argentina, as leituras indicam uma certa paralisia por efeito da dura perseguição do Estado aos intelectuais, como também 
mostram que, diante desta realidade, os pesquisadores buscaram outros países para se formarem ou continuarem sua formação. No caso dos antropólogos ou aspirantes à formação nesta área, o México parece ter sido o país mais procurado e houve amplo acolhimento da parte do IPN.

De igual modo, é importante observar outra diferença entre o campo da etnografia na Argentina e no Brasil: o foco da discussão nas pesquisas analisadas se volta muito mais para a própria compreensão do lugar da antropologia em diálogo com a educação do que para a questão metodológica da etnografia, como pudemos anotar nas pesquisas brasileiras. Tal fato não indica, de modo algum, que não haja discussão metodológica acerca da etnografia na pesquisa argentina, antes disso, aponta claramente que a etnografia, enquanto dimensão fundadora do campo e do trabalho antropológico, já se encontra subentendida na realização das pesquisas em educação naquele país.

Os debates em torno de conceitos como cotidiano e cultura, a questão da mudança social e as tensões postas em jogo nas relações Estado/escola, famílias/escola, saberes discentes/saberes docentes, representações etnocêntricas/desnaturalização de preconceitos e visões de mundo emergem praticamente de todas as pesquisas analisadas como categorias necessariamente articuladas a estas investigações. Assim, nas pesquisas argentinas, não se trata tanto de dizer que se está utilizando o referencial da etnografia, mas sim de se compreender que este fazer antropológico - a partir da concepção do DIE - já se encontra entendido como mecanismo teórico essencial para compreensão da realidade dos problemas educacionais na América Latina.

Podemos inferir, em um primeiro momento, que um dos elementos que embasa o fato da apropriação mais "consistente" da proposta do DIE na Argentina, em comparação com a situação desta proposta no Brasil, decorre da constatação de que, assim como no México, a referida apropriação na Argentina se dá pela via de um constante e atualizado diálogo com a realidade educacional do país. Dessa maneira, no caso argentino, a etnografia do DIE parece não ter adentrado o campo da pesquisa em educação pelo viés de uma "sedução ideológica”, como analisamos no caso brasileiro, estando sua apropriação vinculada muito mais diretamente a um compromisso e à crença na mudança social e compreensão dos fatores étnicos, culturais e sociais que envolvem a construção cotidiana da escola naquele país. Isso indica um "posicionamento político" diante da realidade educacional a partir da própria postura teórico-metodológica assumida nas pesquisas em educação. ${ }^{8}$

Em razão de na Argentina não haver à época um sistema nos modos do portal Capes, cujo acervo se tratou de recurso fundamental para o desenvolvimento desta pesquisa no que tange aos trabalhos brasileiros analisados, tivemos uma enorme dificuldade de encontrar dissertações e teses defendidas na Argentina. Por essa razão, optamos por conhecer as pesquisas por meio de livros e artigos científicos. 


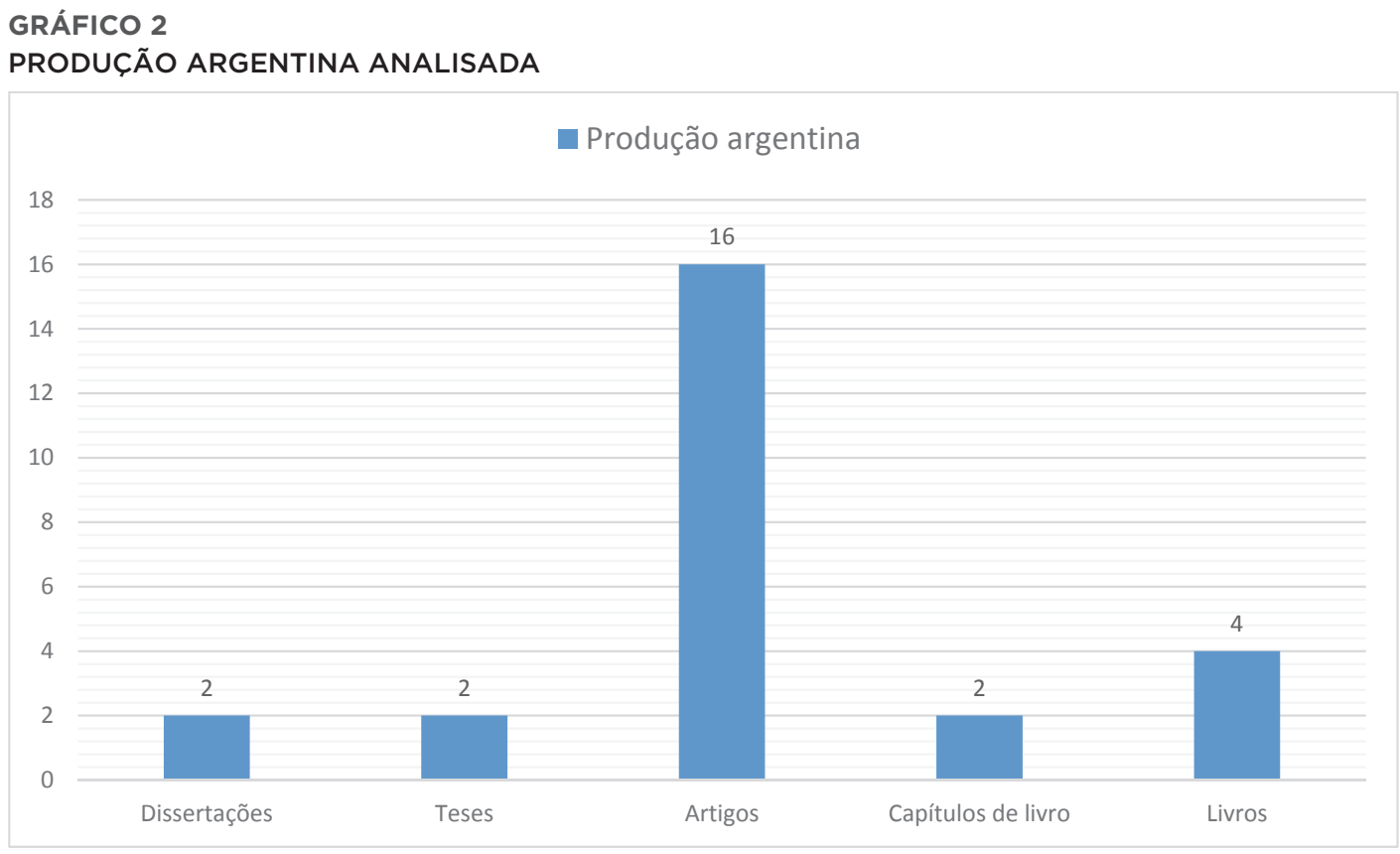

Fonte: Dados da pesquisa.

Isso posto, podemos inferir alguns aspectos importantes e comuns ao conjunto de pesquisas argentinas, tais como a recorrência das temáticas vinculadas ao mundo da infância, da adolescência e da juventude e da docência posta sempre em relação e tensionamento com a instituição escolar e com a sociedade local. A grande motivação traduzida nos objetivos que mobilizaram estas investigações é concentrada nas questões sociais de ordens nacional, regional ou local - seja de corte de classe, de origem (como no caso dos migrantes em áreas de fronteira), de integração ou não com políticas educacionais - e na abordagem das relações escola e família e escola e demais instituições presentes em uma determinada localidade. Nesse contexto, é importante destacar que, em geral, os sujeitos das pesquisas são ouvidos em sua totalidade ou em sua representatividade. A chave teórica e metodológica das investigações é o cotidiano tal como proposto pelo DIE e as lutas dos grupos abordados são analisadas como movimentos de resistência, dos quais a escola é um ator social de relevância.

A pesquisa de campo aparece bastante diversificada e nem sempre podemos afirmar com segurança tratar-se de uma etnografia, mesmo na reinterpretação das pesquisadoras do DIE. Mas as autoras deste Departamento estão presentes na literatura usada nos trabalhos analisados, especialmente Elsie Rockwell.

Fica evidenciado, ainda, com relação à bibliografia, um acúmulo de estudos e pesquisas de autores argentinos que acabam por tornar-se a referência do conjunto da obra. Exemplo disso é a frequência com que Neufeld, Batajan e Thisted são citados nas pesquisas. Em outros 
termos, o que podemos afirmar é que há uma tradição de estudos na antropologia da educação na Argentina em torno de um grupo de pesquisadores que se formaram no México e continuam dialogando com as pesquisadoras e pesquisadores do DIE. A manutenção deste diálogo os mantém atualizados e fortemente sintonizados com o desenvolvimento e as mudanças do próprio DIE.

\section{APONTAMENTOS ANALÍTICOS COMPARATIVOS}

A partir da comparação entre as realidades das antropologias praticadas no Brasil e na Argentina no campo da educação, considerou-se a noção de estilo, uma vez que esta perspectiva possibilita uma análise que não comporta uma hierarquização e tão pouco um estabelecimento de juízo de valor. Ao contrário, permite uma comparação que busca pontuar e analisar semelhanças e diferenças, considerando-se os distintos modos e estilos de antropologia praticados em cada um destes países.

Conforme já mencionado, o contexto histórico latino-americano no qual se desenvolve a proposta do grupo do DIE é marcado por profundas transformações sociais, políticas e culturais que vinham se desenvolvendo desde os anos 1960. Nesse sentido, um conjunto de ações no plano nacional e internacional, tais como as resoluções da Unesco sobre patrimônio (ROCHA, 2009), a crítica cultural da etnografia desencadeada no campo da antropologia (MARCUS; FISCHER, 1986), o crescimento dos movimentos sociais na América Latina e, em particular, no México (WOLF, 2003), contribui para o clima de mudanças que a educação ansiava já por longo tempo.

Pelo levantamento realizado nesta pesquisa, o conjunto da produção das pesquisadoras do DIE reflete bem o espírito desse período de movimentos e transformações sociais, assim como os questionamentos de teorias e enfoques teóricos metodológicos até então predominantes no campo das ciências sociais. Isso traz para o campo da educação a possibilidade de ampliar seus caminhos e olhares sobre a escola, seus processos, práticas e sujeitos envolvidos nos diferentes contextos e processos educativos, tendo em vista a mudança social.

Embora as dissertações e teses analisadas no âmbito da pós-graduação em educação no Brasil apresentem limites de apropriação e aprofundamento dos pressupostos teórico-metodológicos do DIE, como foi possível observar na análise das mesmas, do ponto de vista empírico, a abertura à perspectiva proposta pelo DIE trouxe significativa contribuição para o conhecimento da realidade social brasileira, em geral, e da escola, em particular. Em outras palavras, a abordagem das escolas nas dissertações e teses, nos vários casos analisados, oferece dados significativos sobre a realidade social contemporânea à luz dos movimentos sociais e das políticas públicas de cultura e de educação dos últimos 
30 anos, bem como sobre as "culturas das escolas" e as "culturas nas escolas” em suas singularidades, espalhadas pelo território nacional. Portanto, tal instituição ganha visibilidade a partir desses estudos que tematizam desde os problemas básicos de infraestrutura que afetam o cotidiano das escolas até as relações de poder entre os grupos que as integram, como diretores, professores, alunos e funcionários, passando, também, pelas relações que a escola estabelece com o seu entorno e pela questão da formação e da prática docente.

Sem dúvida alguma, pode-se inferir que o estudo dessas experiências soma para a ampliação do entendimento do campo científico da educação no Brasil em interface com outros campos, como também para os processos futuros de transformação social da escola. De resto, apesar dos limites teórico-metodológicos evidenciados nos trabalhos brasileiros analisados, eles servem para iluminar os pontos que ainda se encontram pouco desenvolvidos.

Um fator diferencial entre as pesquisas brasileiras e argentinas relaciona-se a um dos pilares teórico-metodológicos da proposta do DIE, o qual diz respeito à abrangência contextual da pesquisa. Em outros termos, os processos investigativos não devem ser restritos ao espaço escolar, mas, ao contrário, devem desenvolver-se articulados a outras esferas da realidade investigada, estimulando o pesquisador a analisar toda a dimensão macrossocial associada ao universo e objeto pesquisados. Embora na grande maioria dos estudos brasileiros analisados não tenha sido identificada esta abrangência entre os contextos escolares e as sociedades que o cercam, esta perspectiva está bastante presente nas pesquisas argentinas. É notável o desenvolvimento de estudos que, tendo como objeto a educação, partiram de diferentes recortes e objetos, dentre os quais a realidade de um bairro composto por diferentes etnias, informações de meios midiáticos (como o jornal, por exemplo), bem como em estudos teóricos, também identificados entre as produções que compuseram o leque de análise da pesquisa aqui apresentada.

No caso brasileiro, portanto, poucos trabalhos parecem obter sucesso no sentido proposto pelas autoras. No geral, os textos que mais se aproximam da proposta do DIE-Cinvestav apresentam uma discussão adensada do ponto de vista teórico, porém, avançam pouco em relação à interação com a empiria. Em outras palavras, em geral, a teoria fica de um lado e a empiria do outro, contrariando um dos princípios fundamentais da referida proposta que é a do permanente diálogo no processo da investigação entre os referenciais teóricos e os dados do campo. Distância esta que não se coloca no plano formal de um pensar sobre a ciência apenas, mas que indica uma leitura insuficiente e domínio das escolhas teóricas feitas e indicadas nas teses e dissertações. Nessa direção, é importante ressaltar que, se foram encontrados trabalhos que são marcados pela cisão da teoria com relação à metodologia, foram 
também analisadas dissertações e teses que citaram as mexicanas como uma escolha no estudo da escola, mas, ao longo de seus textos, pouco foi encontrado que ratifique (ou ratificasse) tal escolha. Percebemos a ausência de uma discussão situada no problema e nas indagações da pesquisa, a partir daquelas categorias de base da proposta do DIE como, por exemplo, os conceitos de apropriação, cotidiano, sujeito e hegemonia. Sendo assim, no caso brasileiro, o resultado é um aproveitamento, ainda, incipiente, ficando evidenciada a sedução ideológica da proposta do grupo que, se bem compreendida, não pode ser deslocada e descolada do contexto histórico de seu surgimento. E, ainda, da declarada adesão de seus idealizadores a uma certa linhagem na leitura do marxismo, especialmente com Antônio Gramsci e Agnes Heller.

Outros aspectos que não podem deixar de ser destacados na análise das pesquisas no Brasil, posto que são fundantes e diferenciais da proposta em questão, referem-se, primeiramente, à pouca presença de uma reflexão e análise histórica assumida como uma dimensão necessária à compreensão do fenômeno estudado. Em segundo lugar, o cotidiano escolar como chave de investigação, a partir de Agnes Heller, e nesse o cotidiano escolar não é compreendido ou apreendido analiticamente como histórico, portanto, esfera do fazer político e de exercício das relações de poder e empoderamento. Em terceiro lugar, a pouca correlação analítica empreendida entre as esferas macro e micro, bem como do instituído e do não instituído, ou seja, do que ocorre no interior da escola com o que se passa em seu entorno ou mesmo fora dela, mas que implicam e incidem em suas dinâmicas e interpelam os seus sujeitos.

De um modo geral, a apropriação mais efetiva da proposta do DIE pelos pesquisadores argentinos pode ser explicada pela constituição, quase simultânea, dos campos da antropologia e educação na Argentina e no México, principalmente a partir da presença da pesquisadora argentina Justa Ezpeleta naquele país. Com isso, consolidou-se a articulação entre outros pesquisadores mexicanos e argentinos, desenvolvendo, de modo integrado, diferentemente do caso brasileiro, uma etnografia para a escola na América Latina.

Outro elemento que nos permite afirmar esta aproximação das pesquisas argentinas com o DIE é o fato de que inúmeros pesquisadores argentinos tiveram sua formação diretamente realizada no âmbito daquele Departamento. Isso, certamente, contribuiu para uma compreensão mais aprofundada do referencial teórico-metodológico proposto pelo referido grupo de pesquisa, o que pode ter colaborado para uma apreensão afinada do fazer antropológico. Ao mesmo tempo, parte da deficiência na apropriação da proposta do DIE, no Brasil, deve-se, talvez, ao fato de a área de apropriação ser a pedagogia. Nesse caso, a formação em ciências sociais, em antropologia especificamente, ainda é bastante precária, imprecisa, quando não ausente. ${ }^{9}$ São pedagogos (muitos

9

Sobre o ensino da antropologia em outros cursos que não os das Ciências Sociais, ver o livro organizado por Grossi, Tassinari e Rial (2006) e o conjunto de pesquisas reunidas na Mesa Redonda Antropologia e Educação: um panorama do ensino e da pesquisa no Brasil, realizada na 27a Reunião Brasileira de Antropologia, 2010, e coordenada por Neusa Maria Mendes de Gusmão. 
deles confundindo antropologia com estudos culturais) que tentam se apropriar da etnografia para suas dissertações, sem uma fundamentação teórica mais sistemática e contínua.

\section{CONSIDERAÇÕES FINAIS}

O que é possível apontar com os resultados do projeto de pesquisa "Etnografia para a América Latina - um outro olhar sobre a escola no Brasil e na Argentina”?

Em termos gerais, observa-se uma virada do olhar macro na educação e na escola para um olhar centrado no micro, isto é, do sistema educacional regulado e controlado pelo Estado para o que acontece, de fato, na escola, na sala de aula e em outros espaços. Outra virada diz respeito à adoção de uma mirada qualitativa focada na observação e interação no/do cotidiano escolar e da sala de aula, em lugar da mirada quantitativista. Desta feita, o foco é nos sujeitos, suas ações, práticas e representações.

Assim, pode-se dizer que a leitura das pesquisas brasileiras e argentinas trouxe significativa contribuição para o conhecimento do que “se passa nas escolas". Ou seja, uma compreensão bastante situada no interior da escola, do seu cotidiano, dos espaços, das dinâmicas e práticas que acontecem nesta instituição em relação e tensionamento com outras instituições, políticas públicas e o entorno da escola e que, raramente, eram documentadas ou significadas em pesquisas de natureza quantitativa e nas chamadas investigações orientadas pelas teorias da reprodução.

Pode-se afirmar, a partir dos trabalhos analisados, que a perspectiva das autoras e autores mexicanos possibilitou uma aproximação (e adoção) da etnografia, assumida como uma nova e fecunda perspectiva para as pesquisas no campo da educação, especialmente nas escolas da América Latina. Mas o fato é que essa aproximação e adoção não vieram sempre seguidas de um diálogo mais profundo e necessário com a antropologia e seus aportes teóricos e metodológicos. Isso ocorreu, muitas vezes, por via de uma "importação" do método etnográfico despido do referencial teórico originário, ainda que fosse para estabelecer o diálogo e crítica a este referencial. Tal fato reitera o que alguns outros estudos similares já observam: certa confusão existente entre o que é o empreendimento intelectual na antropologia para se fazer uma etnografia e o estudo qualitativo ou a observação participante. Dito de outra maneira, a apropriação metodológica é entendida ou confundida com procedimentos como convivência e observação na escola ou com a observação participante, que é a referência que mais aparece nas pesquisas analisadas.

Se algumas pesquisas se debruçaram e avançaram na análise da escola tendo como foco as mudanças sociais - outro ponto fundamental da proposta do DIE e notado em grande parte nas pesquisas argentinas -, 
no caso brasileiro, o conjunto das investigações está voltado para questões específicas de alguma área do conhecimento ou disciplina escolar, contrariando, assim, a visão holística proposta pelo DIE e a conjugação do olhar sobre a escola, considerando-se o entorno e as políticas locais e nacionais nas quais a instituição está envolta. Disso decorre, então, a pouca apropriação da perspectiva sócio-histórica apontada pelo DIE para a compreensão do passado e do presente do cotidiano escolar.

De um modo geral, no decorrer de todo este percurso de pesquisa, muitas questões ainda se mostram abertas no que diz respeito à compreensão do lugar da teoria do DIE ou, mais especificamente, da atitude teórica, de fato, assumida pelo grupo, com relação à antropologia e à etnografia. Um desses elementos que nos mobiliza, ainda, refere-se à relação, de certa forma conflituosa, com que as mexicanas nos primeiros tempos do DIE dialogaram com a antropologia, especificamente com a etnografia clássica e a "etnografia” por elas elaborada e proposta como uma metodologia para a pesquisa da escola na realidade latino-americana. Nesse sentido, ao falar da etnografia no contexto da moderna antropologia, Ezpeleta e Rockwell dirigem críticas a este campo, principalmente, por meio de uma compreensão que parece reduzi-lo a uma ciência positivista e descritiva. Seria esta a única e possível leitura da antropologia por não antropólogos nos anos $1980 ?^{10}$

Sintonizados com esta crítica, grupos de pesquisa em antropologia e educação argentinos compreendidos no âmbito desta pesquisa sempre afirmam sua tomada de posição teórico-metodológica como a de um enfoque histórico-etnográfico, de orientação marxista, embora, é necessário ressaltar, a contextualização histórica sempre tenha sido dimensão integradora da etnografia na antropologia. Talvez isso demarque este caráter de diferenciação que configura a etnografia do DIE, residindo ele, mais especificamente, no fato de tal etnografia ter sido constituída enquanto alternativa teórico-metodológica de resistência em determinadas conjunturas históricas no México e na Argentina que afetaram substantivamente a produção científica nesses dois países, como já referido anteriormente.

Entretanto, propor alternativas de pesquisar a escola em sua "positividade" na perspectiva da mudança social levou o DIE à antropologia, em um curioso paradoxo, já que, na visão do Departamento, esta é uma ciência positivista. Ao que parece, a antropologia teve que ser negada (positivismo) para ser reconhecida enquanto ciência da resistência. Em outras palavras, de ciência ou conhecimento identificado com o conservadorismo passou a ciência ou saber interessado na mudança social.

Desse modo, acreditamos que, se o DIE ganha, por um lado, ao se apropriar da antropologia para pesquisar a escola no contexto latino-americano, parece perder por outro, por conta desta leitura particular em que o interesse político que orienta a pesquisa teria, em certa 
medida, reificado o poder da teoria, perdendo de vista o espírito da etnografia (EZPELETA, 1986).

Para finalizar, devemos dizer que tais considerações ainda (in)conclusivas são ricas e abrem um leque de possibilidades na direção de se refletir sobre a riqueza do aprofundamento dos diálogos interdisciplinares movidos pelo espírito crítico e aberto de colaboração com o conhecimento. E, sem dúvida, trilhar pelas lógicas de como ocorrem os usos da antropologia por outros campos, como o educativo, em perspectiva comparada, é uma valiosa contribuição dos mapas teóricos e metodológicos que vamos construindo no empreendimento, nem sempre fácil, de responder aos desafios sociais, particularmente os que dizem respeito à educação e à escola não somente na América Latina, mas também em continentes outros.

\section{REFERÊNCIAS}

ALTHUSSER, Louis. Aparelhos ideológicos de Estado: nota sobre os aparelhos ideológicos de Estado. 3. ed. Rio de Janeiro: Graal, 1998.

BOSI, Alfredo. Dialética da colonização. São Paulo: Companhia das Letras, 1992.

BOURDIEU, Pierre. A reprodução: elementos para uma teoria do sistema de ensino. 3. ed. Rio de Janeiro: Francisco Alves, 1992.

COUTINHO, Carlos Nelson. Um certo senhor Gramsci. Jornal do Brasil, Rio de Janeiro, 29 fev. 1976. Caderno especial, p. 3.

DAUSTER, Tania (Org.) Antropologia: um saber de fronteiras. Rio de Janeiro: Forma Ação, 2007.

ERICKSON, Frederick. Métodos cualitativos de investigación sobre la enseñanza. In: EZPELETA, Justa; ROCKWELL, Elsie. La escuela: relato de un processo de construccion teórica. 1986. Disponível em: <http://www.pedagogica.edu.co/storage/rce/articulos/12_05ens.pdf>. Acesso em: 11 ago. 2010.

GRAMSCI, Antonio. Os intelectuais e a organização da cultura. 3. ed. Rio de Janeiro: Civilização Brasileira, 1979.

GROSSI, Miriam Pillar; RIAL, Carmen; TASSINARI, Antonella (Org.). Ensino de antropologia no Brasil: formação, práticas disciplinares e além-fronteiras. Florianópolis: Nova Letra, 2006.

GUSMÃO, Neusa Maria Mendes de. Antropologia e educação: origens de um diálogo. Cadernos Cedes, Campinas, v. 18, n. 43, p. 8-25, dez. 1997.

GUSMÃO, Neusa Maria Mendes de. Antropologia, estudos culturais e educação: desafios da modernidade. Pro-Posições, v. 19, n. 3, p. 47-82, 2008.

HABERMAS, Jürgen. Teoria de la acción comunicativa I: racionalidad de la acción y racionalización social. Madri: Taurus, 1987.

HELLER, Agnes. 0 cotidiano e a história. São Paulo: Paz e Terra, 1994.

LUKÁCS, György. História e consciência de classe: estudos de dialética marxista. Rio de Janeiro: Elfos, 1978.

MARCUS, George; FISCHER, Michael. Anthropology as cultural critique: an experimental moment in the human sciences. Chicago: The University of Chicago Press, 1986.

MINAYO, Maria Cecília de Souza. Hermenêutica-dialética como caminho do pensamento social. In: MINAYO, Maria Cecília de Souza; DESLANDES, Suely Ferreira (Org.). Caminhos do pensamento: epistemologia e método. Rio de Janeiro: Fiocruz, 2002. p. 83-107. 
NEUFELD, Maria Rosa. El campo de la antropología y la educación en la Argentina: problemáticas y contextos. In: WORKSHOP DIÁLOGOS IBERO-AMERICANOS SOBRE

ETNOGRAFIA NA EDUCAÇÃO, 2011. Belo Horizonte. Anais... Belo Horizonte: PUC-Minas, 2011.

OLIVEIRA, Roberto Cardoso; RUBEN, Guilhermo Raul (Org.). Estilos de antropologia. Campinas: Editora da Unicamp, 1995.

PEREIRA, Alexandre Barbosa. "A maior zoeira”: experiências juvenis na periferia de São Paulo. 2010. 262 f. Tese (Doutorado em Antropologia Social) - Universidade de São Paulo, São Paulo, 2010.

ROCHA, Gilmar. Aprendendo com o outro: Margaret Mead e o papel da educação na organização da cultura. In: DAUSTER, Tânia; TOSTA, Sandra; ROCHA, Gilmar. Etnografia 8 educação: culturas escolares, formação e sociabilidades infantis e juvenis. Rio de Janeiro: Lamparina, 2012.

ROCHA, Gilmar; TOSTA, Sandra Pereira. Antropologia \& educação. Belo Horizonte: Autêntica, 2009.

ROCKWELL, Elsie. Reflexiones sobre el proceso etnográfico (1982-1985). México: Departamento de Investigaciones Educativas, Centro de Investigaciones y Estudos Avanzados del IPN, 1987.

ROCKWELL, Elsie. La relevancia de la etnografía para la transformación de la escuela. In: SEMINARIO NACIONAL DE INVESTIGACIÓN EN EDUCACIÓN, 3. Bogotá. 1992. Memorias... Bogotá: Centro de Investigación de La Universidad Pedagógica; Instituto Colombiano para El Fomento de La Educación Superior, 1992. p. 14-29.

ROCKWELL, Elsie; EZPELETA, Justa. A pesquisa participante. São Paulo: Cortez, Autores Associados, 1989.

ROESSNER, David. Quantitative and qualitative methods and measures in the evaluation of research. Research Evaluation, Oxford, UK, v. 9, n. 2, p. 125-132, 2000.

SANCHIS, Pierre. Da quantidade à qualidade. Como detectar as linhas de forças antagônicas de mentalidades em diálogo. Revista Brasileira de Ciências Sociais, São Paulo, v. 12, n. 33, fev. 1997.

SOARES, Magda Becker. Alfabetização no Brasil: o estado do conhecimento. Brasília: Inep/MEC, 1989.

THOMPSON, Edward. P. A formação da classe operária inglesa. São Paulo: Paz e Terra, 1987.

TOSTA, Sandra Pereira et al. Etnografia para a América Latina: um outro olhar sobre a escola no Brasil e na Argentina. Relatório técnico-científico do CNPq. Belo Horizonte: PUC-Minas, 2011.

TOSTA, Sandra Pereira et al. Etnografia para a América Latina: um outro olhar sobre a escola no Brasil e na Argentina. Relatório Técnico-Científico do CNPq. Belo Horizonte: PUC-Minas, 2012.

WOLF, Eric. Tipos de campesinato latino-americano: uma discussão preliminar. In: FELDMAN-BIANCO, Bela; LINS RIBEIRO, Gustavo (Org.). Antropologia e poder. Brasília: EdUnB; Campinas: Editora da Unicamp, 2003.

\section{SANDRA FÁTIMA PEREIRA TOSTA}

Pontifícia Universidade Católica de Minas Gerais - PUC-Minas -, Belo Horizonte, Minas Gerais, Brasil sandra@pucminas.br

\section{WESLEI LOPES SILVA}

Pontifícia Universidade Católica de Minas Gerais - PUC-Minas -, Belo Horizonte, Minas Gerais, Brasil; Universidade de Itaúna - UIT -, Itaúna, Minas Gerais, Brasil wesleilop@gmail.com 